3.

Derecho del trabajo 

Revista de Derecho

de la Pontificia Universidad Católica de Valparaíso

XXIX (Valparaíso, Chile, $2^{\text {do }}$ Semestre de 2007)

[pp. 171 - 202]

\title{
OPORTUNIDADES DE CONCILIACIÓN DE TRABAJO Y VIDA FAMILIAR EN LA LEGISLACIÓN LABORAL CHILENA
}

[Possibilities to Reconcile Work and Family Life in the Chilean Labour Legislation]

\author{
Eduardo CaAmaño Rojo* \\ Pontificia Universidad Católica de Valparaíso
}

\section{RESUMEN}

La incorporación masiva de la mujer al trabajo ha motivado uno de los cambios sociales más profundos del último tiempo, lo que hace necesario configurar un nuevo modo de cooperación y compromiso entre mujeres y hombres que permita un reparto equilibrado de responsabilidades en la vida familiar y profesional. Por este motivo, el tema de la conciliación entre trabajo y vida familiar es de enorme importancia para asegurar la igualdad de oportunidades en el empleo, permitiendo afianzar las posibilidades de un desarrollo armónico, equitativo y solidario. Con todo, el avance en esta materia es aún incipiente, por tal motivo este trabajo pretende efectuar un aporte desde la perspectiva del Derecho del Trabajo y analizar críticamente las oportunidades de conciliación de trabajo y vida familiar que reconoce la legislación laboral para contribuir a sentar las bases de una amplia discusión de este tema en Chile.

Palabras clave: Derecho - trabajo - conciliación - familia - trabajador - igualdad de trato.

\section{Abstract}

The fact that women have incorporated massively to work has resulted in one of the deepest social changes in recent times. This demands the configuration of a new manner of cooperation and commitment between women and men, to allow a balanced distribution of responsibilities both in family and professional life. This is why the reconciliation between work and family life is such an important issue, to insure equal opportunities in jobs, allowing the strengthening of the possibilities of a harmonic, fair and supportive development. All in all, this issue is beginning to develop. This work attempts to contribute, from the Labour Law perspective, and to critically analyse the possibilities to reconcile work and family life that the labour legislation recognises in order to lay the foundations for an ample discussion of this issue in Chile.

KeYwords: Law - work - reconciliation - family - employee - equal treatment.

* Profesor de Derecho del Trabajo en la Facultad de Derecho de la Pontificia Universidad Católica de Valparaíso. Dirección postal: Avda. Brasil 2950, Valparaíso, Chile. Correo electrónico: eduardo.caamano@ucv.cl 


\section{INTRODUCCIÓN}

Los cambios sociales y económicos que han tenido lugar en el último tiempo en nuestro país ${ }^{1}$, han favorecido una progresiva incorporación de la mujer al mercado laboral, lo que ha ido acompañado de una serie de transformaciones en otras áreas de la vida social, como es el caso de la organización familiar tradicional ${ }^{2}$, el cuidado de los hijos o la ejecución de las tareas domésticas cotidianas. Esta nueva realidad coloca a hombres y mujeres en una situación más confusa y compleja desde el punto de vista de la asunción de sus responsabilidades familiares, pues deben responder simultáneamente a demandas de tiempo y tareas como padres, cónyuges y trabajadores ${ }^{3}$. Por lo anterior, en la búsqueda de soluciones que hagan posible dar cuenta de esta realidad social y laboral diversa, se hace necesario identificar los procesos de conflicto en la compatibilidad entre familia y trabajo, ya que sus efectos incidirán, por ejemplo, en el desarrollo de los hijos, la igualdad de oportunidades en el empleo, la productividad, el acceso a la capacitación o la motivación laboral ${ }^{4}$. De esta manera, entonces, resulta evidente que una reflexión sobre el tema es importante para un país que aspira a crecer con equidad y solidaridad, teniendo en cuenta que la familia, como lo dispone expresamente el artículo $1^{\circ}$ de la Constitución Política de la República constituye el núcleo esencial de nuestra sociedad.

Desde una perspectiva de género, el tema de la conciliación entre la

${ }^{1}$ Véase: CaAmaño, Eduardo, Las transformaciones del trabajo, la crisis de la relación normal y el desarrollo del empleo atipico, en Revista de Derecho 18 (Universidad Austral de Chile, julio 2005), pp. 25 s.

${ }^{2}$ Sobre la materia: Martínez, Jesús, Nuevas formas de familia y Derecho del Trabajo $y$ de la Seguridad Social, en Borrajo, Efrén (Editor), Nueva sociedad y Derecho del Trabajo (Madrid, 2004), pp. 5 s.

${ }^{3}$ En este sentido: Servicio Nacional de la Mujer, Análisis de los costos y beneficios de implementar medidas de conciliación de vida laboral y familiar en la empresa, en Documento de Trabajo No 84 (2003), p. 3: "Una de las consecuencias de estos cambios sociodemográficos es el incremento en los conflictos trabajo-familia. No sólo para las mujeres, quienes siguen asumiendo una mayor responsabilidad en el cuidado de la familia. Ellas ahora, no sólo tienen que combinar dos cargas de trabajo, sino que también se ven presionadas a cumplir ambas tareas con un alto nivel de excelencia. Pero, el conflicto también afecta a los hombres, que producto de la incorporación de la mujer al mercado de trabajo y la consecuente tensión en el ejercicio de roles, deben hacerse cargo de parte de las responsabilidades familiares". Véase también: Martínez, María Pilar, El papel de las relaciones familiares en el ajuste familia-trabajo, en CARRASCO, María José - GARCÍA-Mina, Ana (editoras), El ajuste trabajo-familia desde una perspectiva de género (Madrid, 2005), pp. 53 s.

${ }^{4}$ Carrasco, María José - García-Mina, Ana, El ajuste trabajo-familia desde una perspectiva de género, ob. cit., pp. 9-10. 
vida laboral y familiar de trabajadores y trabajadoras puede ser revisado fundamentalmente desde dos polos. Por una parte, está el mundo privado, donde se encuentran la familia y los espacios personales. Desde este polo, se pueden explorar los arreglos mediante los cuales los trabajadores y trabajadoras concilian ambos mundos: las redes sociales, las redes institucionales, los efectos (impactos) sociales y familiares de las diversas formas de conciliación o la falta de ellas en cada uno de los miembros de las familias. En el otro polo, se encuentra el mundo laboral: hombres y mujeres en su rol de trabajadores y trabajadoras, las exigencias de este ambiente que determinan la racionalidad de funcionamiento de la empresa, la tensión entre esta lógica y las necesidades de conciliación de los trabajadores, el acceso desigual de hombres y mujeres al mercado de trabajo, etc. ${ }^{5}$. Es precisamente este segundo polo, desde una dimensión jurídica, el que interesa a este estudio.

En efecto, el análisis jurídico resulta de vital importancia, pues la regulación legal destinada a proteger al trabajador fue dictada en un contexto social distinto en el que no se presentaban conflictos en la asunción de responsabilidades laborales y familiares, ya que éstas últimas eran asumidas preponderantemente por mujeres, correspondiéndole al hombre el rol básico de trabajar a tiempo completo y procurar los ingresos para el grupo familiar. A su vez, adquiere realce un estudio de esta nueva realidad social desde la perspectiva del Derecho del Trabajo, ya que nuestro ordenamiento jurídico ha venido experimentando modificaciones inorgánicas en los últimos años con el fin de dar respuestas parciales a esta nueva realidad laboral y familiar en la que se encuentran insertos hombres y mujeres, sin que puedan mostrarse aún avances significativos, todo lo cual termina repercutiendo negativamente frente a un efectivo reconocimiento de la igualdad de oportunidades en el empleo y tiende, sobre todo, a perpetuar la ya desmejorada situación laboral de la mujer. Además, cabe tener en cuenta que periódicamente se implementan medidas de política social tendientes a permitir que un mayor número de mujeres se incorpore al mercado de trabajo formal, por ejemplo, a través del establecimiento de salas cunas financiadas por el Estado, pero se ha obviado revisar el contenido tradicional de la regulación de la jornada de trabajo, actualizar el sistema legal de protección a la maternidad o avanzar en la regulación de formas atípicas de contratación laboral, lo que termina afectando directamente la eficacia de estas medidas y la legítima aspiración de muchas

${ }^{5}$ Servicio Nacional de la Mujer, Conciliación entre la vida familiar y la vida laboral de trabajadores y trabajadoras chilenos/as, en Documento de Trabajo No 76 (2002), p. 4. 
trabajadoras de tener un mejor nivel de vida y así, en muchos casos, poder superar la línea de la pobreza. De igual manera, no es posible obviar que muchos hombres comienzan a demandar más y mejores posibilidades para asumir sus responsabilidades familiares, lo que entra en conflicto con un ordenamiento jurídico laboral que parte del supuesto de que esas tareas le corresponden exclusivamente a las mujeres.

Por todo lo expuesto, en el Derecho del Trabajo contemporáneo ha ido adquiriendo paulatinamente importancia el tema de la conciliación de la vida familiar y laboral ${ }^{6}$, lo que ha generado la necesidad de replantear muchas instituciones propias y tradicionales de esta rama del Derecho, pues éstas fueron dictadas en un contexto social diferente caracterizado por una baja tasa de participación laboral femenina y, además, sin cuestionamientos de un modelo social que hoy parece cada vez más anacrónico, a saber: el rol del hombre como proveedor, dedicado al trabajo productivo remunerado de tiempo completo, y el de la mujer como cuidadora de la familia y el hogar común ${ }^{7}$.

Por lo tanto, la creciente incorporación de la mujer al mundo del trabajo, sin exoneración de las responsabilidades familiares que tradicionalmente le han sido asignadas, ha ocasionado una constante tensión entre sus obligaciones laborales y sus tareas maternales, la que sólo puede ceder ante una solución equilibrada que tome como premisa fundamental el valor social de la maternidad y de la paternidad, y la formulación de una normativa que la tome en consideración en su justa medida ${ }^{8}$. Además, como lo manifiesta acertadamente el informe final del Comité de Expertos de la Conferencia de Nantes de $1997^{\circ}$, la igualdad entre hombres y mujeres

\footnotetext{
${ }^{6}$ Un estudio profundo sobre la materia se encuentra en: Borrajo, Efrén (Editor), Nueva sociedad y Derecho del Trabajo (Madrid, 2004).

${ }^{7}$ En detalle: Todaro, Rosalba - YÁNÉE, Sonia, El trabajo se transforma. Relaciones de producción y relaciones de género (Santiago, 2004), pp. 64 s.; Hein, Catherine, Conciliar trabajo y las responsabilidades familiares. Ideas prácticas de la experiencia global, en Colección Informes de la Organización Internacional del Trabajo (Ministerio del Trabajo y Asuntos Sociales, Madrid, 2006), pp. 26 s.

${ }^{8}$ En este sentido, Orellana, Ana María, Medidas para promover la conciliación de la vida familiar y laboral de las personas trabajadoras. Análisis de las Directivas Comunitarias 92/85 y 96/34 y lagunas en su transposición al ordenamiento interno español, en Revista del Ministerio del Trabajo y Asuntos Sociales 37 (Madrid), p. 61, disponible en www.mtas.es. De igual manera: Binnstock, Hanna, Hacia la igualdad de la mujer. Avances legales desde la aprobación de la Convención sobre eliminación de todas las formas de discriminación contra la mujer, en Serie Mujer y Desarrollo No 24 (CEPAL, 1998), p. 39.

${ }^{9}$ Groupe D' Experts invitées à la discussion du rapport intermédiaire, Transformation du travail et devenir du droit du travail en Europe (Conférence de Nantes, 25
} 
desde el punto de vista del empleo, implica necesariamente la existencia de condiciones iguales con respecto al tiempo de trabajo remunerado, el tiempo de trabajo no remunerado (destinado al trabajo en el hogar y a la formación) y el tiempo de descanso. Por tal motivo, este Comité considera que la igualdad entre hombres y mujeres en el empleo aparece estrechamente vinculada con el derecho al respeto de la vida privada y familiar ${ }^{10}$.

En lo que respecta al desarrollo de la temática de la conciliación de trabajo y vida familiar en Chile, es preciso señalar que ella ha sido objeto de escasa atención ${ }^{11}$, tanto desde la óptica del Derecho del Trabajo, como desde una visión más amplia de política social y laboral, pese a que en los ordenamientos jurídicos comparados, especialmente de los países miembros de la Unión Europea ${ }^{12}$, ocupa hace un tiempo un lugar importante en las

de octubre 1997), Rapport final (1998), p. 81.

${ }^{10}$ Sobre el tratamiento del tema de conciliación de trabajo y vida familiar en el sistema jurídico de la Unión Europea: ToRTUERo, José Luis, 50 propuestas para racionalizar la maternidad y facilitar la conciliación laboral (Navarra, 2006), pp. $46 \mathrm{~s}$.

${ }^{11}$ Entre los escasos estudios realizados sobre la materia hasta la fecha destaca: Servicio Nacional de La Mujer, Análisis sobre experiencias en empresas sobre compatibilización de vida laboral y familiar, en Documento de Trabajo No 67 (1999); Servicio Nacional de la Mujer, Conciliación entre la vida familiar y la vida laboral de trabajadores y trabajadoras chilenoslas, ob. cit.; ARRIAGADA, Irma, Los limites del uso del tiempo: dificultades para la conciliación de familia y trabajo, en Politicas hacia las familias, protección e inclusión sociales (CEPAL, Reunión de Expertos, 28 y 29 de junio de 2005), disponible en: www.cepal.cl; CaAmaño, Eduardo, Conciliación de trabajo y vida familiar. Un análisis desde la perspectiva del Derecho del Trabajo, en Revista de Derecho (Universidad Austral de Chile, julio 2004), pp. 59 s.

${ }^{12}$ Ejemplos en este sentido son: la ley espańola № 39/1999 de fecha 5 de noviembre de 1999 que promueve la conciliación de la vida familiar y laboral de las personas trabajadoras. Una mención especial merece la Carta de Derechos Sociales a la Constitución Europea, la que en su artículo 16 incluyó una norma explícita sobre la promoción de la compatibilización de las obligaciones profesionales y familiares en el marco del derecho a la igualdad de trato entre hombres y mujeres. Conforme a esta disposición: (inciso 10) "Debe garantizarse la igualdad de trato entre hombres y mujeres. Debe desarrollarse la igualdad de oportunidades entre hombres y mujeres". (inciso 2०) "A tal fin, conviene intensificar, dondequiera que ello sea necesario, las acciones destinadas a garantizar la realización de la igualdad entre hombres y mujeres, en particular para el acceso al empleo, la retribución, las condiciones de trabajo, la protección social, la educación, la formación profesional y la evolución de la carrera profesional". (inciso $3^{\circ}$ ) "Conviene, asimismo, desarrollar medidas que permitan a hombres y mujeres compaginar más fácilmente sus obligaciones profesionales y familiares". Para mayor información véase: GIL y GIL, José Luis - UshaKova, Tatsiana, Los derechos sociales en la Carta de los Derechos Fundamentales de la Unión Europea, disponible en: http://www. uv.es/CEFD/5/gil.html. 
respectivas agendas legislativas ${ }^{13}$. Por este motivo, resulta evidente que es necesario dar inicio a una reflexión más explícita y completa de esta materia en nuestro país a la luz de la actual normativa laboral ${ }^{14}$, como a su vez de la experiencia comparada derivada de sistemas jurídicos más avanzados en este tema ${ }^{15}$, a objeto de poder contribuir desde el ámbito académico a la concreción de una distribución más equitativa de roles entre madres y padres trabajadores que permita materializar un cambio en nuestro mercado de trabajo. De esta manera sería posible lograr que muchas madres trabajadoras no se vean en la necesidad de renunciar o postergar su desarrollo laboral y profesional, realizando mayoritariamente trabajos residuales o más precarios, con lo que, en los hechos, se está afectando directamente la igualdad de oportunidades en el empleo, sus posibilidades de desarrollo profesional y laboral, así como su futuro previsional al momento de pensionarse por vejez ${ }^{16}$. A su vez, un mayor desarrollo de este tema posibilitaría

${ }^{13}$ En este sentido se encuentra el artículo 19 de la Carta Comunitaria de Derechos Sociales Fundamentales, de fecha 19 de diciembre de 1989; la Directiva 75/117/CEE de 10 de febrero de 1977 sobre la aplicación del principio de igualdad de retribuciones entre los trabajadores masculinos y femeninos; la Directiva 76/207/ CEE de 9 de febrero de 1976 sobre la aplicación del principio de igualdad de trato entre hombres y mujeres en cuanto al acceso al empleo, a la formación y a la promoción profesional y a las condiciones de trabajo; la Directiva 92/85/ CEE de 19 de octubre de 1992 sobre aplicación de medidas para promover la mejora de la seguridad y de la salud en el trabajo de la mujer embarazada, que haya dado a luz o esté en período de lactancia; y la Directiva 96/34/ CEE de 3 de junio de 1996 sobre permiso parental y la ausencia del trabajo para conciliar la vida profesional y laboral y promover la igualdad de oportunidades y de trato entre hombres y mujeres.

${ }^{14}$ Sobre el particular cabe destacar que el Servicio Nacional de la Mujer se encuentra elaborando un proyecto de ley de conciliación de vida laboral y familiar, en virtud del cual se pretende modificar normas en materia de jornada de trabajo, de reglamento interno, de capacitación ocupacional y, en particular, fortalecer los derechos de protección a la maternidad en busca de equilibrar las obligaciones y responsabilidades de ambos padres en el cuidado y atención de sus hijos.

${ }^{15}$ Este es el caso de España, país en el que desde el año 1989 se han venido dictando sistemáticamente un conjunto de leyes destinadas a promover la conciliación de trabajo y vida familiar y a generar cambios en su normativa laboral. En detalle TORTUERo, José Luis, 50 propuestas para racionalizar la maternidad y facilitar la conciliación laboral, ob. cit., pp. 56 s. Sobre la experiencia de Dinamarca véase: http://www.mtas. es/mundo/Revista/Revista103/116.pdf.

${ }^{16}$ De acuerdo con el artículo 3 del Decreto Ley N³.500, que crea el Nuevo Sistema de Pensiones, las mujeres se pueden pensionar a partir de los sesenta años de edad. Si se tiene en cuenta que las trayectorias laborales de las mujeres son por regla general más discontinuas que las de los hombres, que sus remuneraciones son inferiores, que tienen mayores expectativas de vida y que se pensionan por vejez con menor edad que los hombres, resulta fácil prever un panorama social bastante desolador y preocupante 
que los padres trabajadores revaloricen el tiempo dedicado a la familia y al cuidado de los hijos y asuman más abiertamente sus responsabilidades familiares en un contexto social que comienza rápidamente a priorizar la dualidad de roles de hombres y mujeres en el trabajo y en el hogar.

El presente estudio se centrará en identificar y analizar los principales acuerdos internacionales ratificados por Chile que tienen directa incidencia en la formulación de una respuesta jurídica a la necesidad de conciliación de trabajo y vida familiar, como a su vez, se sistematizarán y evaluarán críticamente las actuales disposiciones del Código del Trabajo (ст.) que reconocen derechos a los trabajadores que posibilitan un cierto de grado de armonización de sus responsabilidades laborales y familiares. A través de este enfoque se prende establecer que existen dos vías a través de las cuales se está manifestando la urgencia de adecuar nuestra normativa laboral en aras de alcanzar una mayor compatibilización entre trabajo y vida familiar: por un lado, la necesidad de que Chile cumpla con los compromisos derivados de la suscripción de importantes acuerdos internacionales, los que importan la implementación efectiva de mecanismos de fomento, reformas legales y de políticas sociales que contribuyan a materializar la igualdad de oportunidades en el empleo de hombres y mujeres. Por otro lado, la insuficiencia de la actual normativa laboral para responder a los nuevos requerimientos de trabajadoras y trabajadores frente a la armonización de sus responsabilidades en el trabajo y la familia exige que se estudie la forma perfeccionar nuestro ordenamiento jurídico ante una realidad que se aleja a pasos agigantados de los cimientos patriarcales propios del modelo fordista de organización empresarial, el cual se estructuraba sobre la base de la contratación masiva, a tiempo completo y de duración indefinida de trabajadores de sexo masculino ${ }^{17}$.

\section{ACUERDOS INTERNACIONALES SUSCRITOS POR CHILE QUE INCIDEN EN LA NECESIDAD DE FACILITAR LA CONCILIACIÓN DE TRABAJO Y FAMILIA}

\section{Convenio $N^{o} 156$ de la OIT sobre trabajadores con responsabilidades} familiares.

En el plano estrictamente laboral, cumple un rol importante con ocasión del tema en estudio el Convenio No 156 de la Organización Internacional del Trabajo (огт) sobre los trabajadores con responsabilidades

en el futuro inmediato en el que una gran cantidad de mujeres trabajadoras en Chile comiencen a jubilar.

${ }^{17}$ Véase: CAAMAÑo, Eduardo, Las transformaciones del trabajo, la crisis de la relación normal y el desarrollo del empleo atípico, ob. cit., pp. $37 \mathrm{~s}$. 
familiares $^{18}$, más aún, si se considera que este instrumento internacional ha sido ratificado expresamente por Chile, con fecha 14 de octubre de 1994. El Convenio No 156 surge de la preocupación de la OIT por complementar los acuerdos adoptados en materia de no discriminación en el empleo (Convenio No 111 de 1958) y de igualdad de remuneración entre hombres y mujeres (Convenio No 100 de 1951), pues ellos no hacen referencia a los trabajadores con responsabilidades familiares, quienes se han visto enfrentados a diferenciaciones de trato y menores posibilidades de integración al mercado de trabajo, no excluidas por dichos acuerdos internacionales. Por tal motivo, a juicio de este organismo internacional, es necesario "instaurar la igualdad efectiva de oportunidades y de trato entre trabajadores de uno y otro sexo con responsabilidades familiares, al igual que entre éstos y los demás trabajadores". De esta manera, y a través de la adopción de medidas especiales, se hará posible evitar que los problemas con que se enfrentan todos los trabajadores, se agraven respecto de aquellos que tienen responsabilidades familiares.

El artículo 1 de este Convenio define a los "trabajadores con responsabilidades familiares", como aquellos trabajadores y trabajadoras con responsabilidades hacia los hijos a su cargo, cuando tales responsabilidades limiten sus posibilidades de prepararse para la actividad económica y de ingresar, participar y progresar en ella. Asimismo, el inciso $2^{\circ}$ de este artículo comprende dentro del concepto de trabajadores con responsabilidades familiares, a los trabajadores y trabajadoras con responsabilidades respecto de otros miembros de su familia directa que de manera evidente necesiten de su cuidado o sostén, cuando tales responsabilidades limiten sus posibilidades de prepararse para la actividad económica y de ingresar, participar y progresar en ella. Este sería el caso, por ejemplo, de personas que asumen el cuidado de familiares directos que se encuentran en la tercera edad o que padecen de discapacidad.

De la definición anterior destaca, en primer lugar, que el Convenio coloca en igualdad de condiciones respecto de la aplicación de las medidas especiales que contempla, tanto a hombres como a mujeres que tengan la calidad de trabajadores. En segundo lugar, constituye una importante innovación que la extensión de la responsabilidad familiar no se limita sólo a los hijos, sino que comprende también, con bastante realismo, a otros familiares directos que puedan requerir cuidado o asistencia, lo que suele

\footnotetext{
${ }^{18}$ Este Convenio fue aprobado por la Conferencia General de la OIT, con fecha 23 de junio de 1981. Véase también la Recomendación No 165 sobre los trabajadores con responsabilidades familiares aprobada por la Conferencia General de la OIT con fecha 3 de junio de 1981.
} 
involucrar a un número significativo de personas en los países en desarrollo, en los que la escasez de instancias o establecimientos que den asistencia a personas en edad senil o inválidas o que requieran de algún tipo especial de atención, origina que sus familiares directos, sobre todo mujeres, deban asumir su cuidado, postergando o renunciando a su carrera profesional. En tercer lugar, llama la atención que la necesidad de protección de estos trabajadores viene dada, porque la asunción de una responsabilidad familiar limita sus posibilidades de prepararse para la actividad económica, como asimismo, de ingresar, participar y progresar en ella, lo que coloca a estas personas en una situación desventajosa que amerita que se les otorgue una protección especial que les garantice que no sean objeto de prácticas o medidas discriminatorias en el empleo.

Por otra parte, en lo que respecta al ámbito de aplicación de este Convenio, debemos señalar que éste es amplio, pues comprende "todas las ramas de actividad económica y todas las categorias de trabajadores" sin distinción alguna (artículo 2). Ahora bien, para los efectos de avanzar hacia la concreción de la igualdad de oportunidades de estos trabajadores, se establece una importante obligación para los Estados en el artículo 3 inciso $1^{\circ}$, pues éstos deberán "incluir dentro de los objetivos de su política nacional el permitir que las personas con responsabilidades familiares que desempeñen o deseen desempeñar un empleo ejerzan su derecho a hacerlo sin ser objeto de discriminación ${ }^{19} y$, en la medida de lo posible, sin conflicto entre sus responsabilidades familiares y profesionales". Con esto, se reafirma que el fin de asegurar la igualdad de oportunidades de los trabajadores con responsabilidades familiares debe ser, ante todo, un principio o una idea rectora que inspire e integre las políticas sociales del Estado.

Para el cumplimiento del objetivo central antes indicado, los artículos 4 y 5 del Convenio disponen que los Estados deberán adoptar todas las medidas compatibles con las condiciones y posibilidades nacionales para: i) permitir a los trabajadores con responsabilidades familiares el ejercicio de su derecho a elegir libremente su empleo; ii) tener en cuenta sus necesidades en lo que concierne a las condiciones de empleo y a la seguridad social; iii) tener en cuenta las necesidades de los trabajadores con responsabilidades familiares en la planificación de las comunidades locales o regionales; y iv)desarrollar o promover servicios comunitarios, públicos o privados, tales como los servicios y medios de asistencia a la infancia y de asistencia familiar.

${ }^{19}$ Para los efectos de este Convenio el término discriminación debe entenderse según la definición contenida en el artículo 1 del Convenio No 111 de la OIT de 1958. 
Asimismo, el artículo 6 del Convenio, reconociendo que la situación social y laboral que enfrentan los trabajadores con responsabilidades familiares tiene un importante componente cultural como base, dispone que: "las autoridades y organismos competentes de cada pais deberán adoptar medidas apropiadas para promover mediante la información y la educación una mejor comprensión por parte del público del principio de la igualdad de oportunidades y de trato entre trabajadores y trabajadoras y acerca de los problemas de los trabajadores con responsabilidades familiares, asi como una corriente de opinión favorable a la solución de estos problemas". A su vez, en concordancia con lo anterior, el artículo 7 señala que: "deberán tomarse medidas compatibles con las condiciones y posibilidades nacionales, incluyendo medidas en el campo de la orientación y de la formación profesionales, para que los trabajadores con responsabilidades familiares puedan integrarse y permanecer en la fuerza de trabajo, asi como reintegrarse a ella tras una ausencia debida a dichas responsabilidades".

Desde la perspectiva referida a la regulación jurídica del trabajo subordinado, el artículo 8 prescribe que la responsabilidad familiar no debe constituir de por sí una causa justificada para poner fin a la relación de trabajo, con lo cual esta norma plantea que los Estados busquen soluciones que permitan efectivamente conciliar trabajo y familia a los trabajadores que no están en condiciones de prestar servicios a tiempo completo, lo que podría lograrse, por ejemplo, a través de la promoción de empleos a tiempo parcial $^{20}$.

Finalmente, el artículo 9 del Convenio prescribe que sus "disposiciones podrán aplicarse por vía legislativa, convenios colectivos, reglamentos de empre$s a$, laudos arbitrales, decisiones judiciales, o mediante una combinación de tales medidas, o de cualquier otra forma apropiada que sea conforme a la práctica nacional y tenga en cuenta las condiciones nacionales". De esta forma, se ha establecido un marco amplio y flexible para que los Estados miembros de la oIT comiencen a diseñar políticas sociales en las que se incluya el tema y la problemática asociada a la situación económica, social y laboral de los trabajadores con responsabilidades familiares. Así se espera que esta materia se analice y se discuta sobre la base de las circunstancias o prácticas propias de esa realidad nacional y, en último término, se diseñen y se apliquen medidas específicas conforme a esa realidad -entre las cuales podrían incluirse propuestas de modificación a la legislación laboral- tendientes a concretizar efectivamente el derecho de estos trabajadores a participar en la vida económica y laboral con igualdad de oportunidades frente a los otros

${ }^{20}$ Sobre la materia: CAAmaño, Eduardo, El trabajo a tiempo parcial (Santiago, 2007), pp. 70 s. 
trabajadores que no tienen responsabilidades de carácter familiar.

2. Convención sobre eliminación de todas las formas de discriminación contra la mujer.

La Convención sobre eliminación de todas las formas de discriminación en contra de la mujer ${ }^{21}$, entre otras materias ${ }^{22}$, ha reconocido explícitamente la importancia de que los Estados Partes avancen hacia la concreción de un sistema que garantice una adecuada conciliación entre trabajo y familia. Es así, como este instrumento internacional reconoce en su parte considerativa "el gran aporte de la mujer al bienestar de la familia y al desarrollo de la sociedad, hasta ahora no plenamente reconocido, la importancia social de la maternidad y la función de los padres en la familia y educación de los hijos". Asimismo, se afirma que: "el papel de la mujer en la procreación no debe ser causa de discriminación, sino que la educación de los hijos exige la responsabilidad compartida entre hombres y mujeres y la sociedad en su conjunto". Por lo anterior, se manifiesta también en este instrumento que "para lograr la plena igualdad entre el hombre y la mujer es necesario modificar el papel tradicional tanto del hombre como de la mujer en la sociedad y en la familia", cuyo mayor impacto precisamente se manifiesta en el plano del empleo.

Por su parte, en el plano de las obligaciones impuestas por esta Convención, desde el punto de vista de la participación de la mujer en el trabajo, merece especial atención el artículo 11 apartado 2, letra c) conforme con el cual: "A fin de impedir la discriminación contra la mujer por razones de matrimonio o maternidad y asegurar la efectividad de su derecho a trabajar, los Estados Partes tomarán medidas adecuadas para: c) Alentar el suministro de los servicios sociales de apoyo necesarios para permitir que los padres combinen las obligaciones para con la familia con las responsabilidades del trabajo y la participación en la vida pública, especialmente mediante el fomento de la creación y desarrollo de una red de servicios destinados al cuidado de los niños".

De la disposición citada se destaca que se les ha entregado a los Estados

${ }^{21}$ Esta Convención fue adoptada por la Conferencia General de Naciones Unidas mediante Resolución No 34/189 de fecha 18 de diciembre de 1979 y entró en vigor el día 3 de septiembre de 1981. Por su parte, Chile la ratificó con fecha 8 de diciembre de 1989.

${ }^{22}$ Véase: Galdames, Liliana, La discriminación de la mujer ante el derecho internacional. Convención sobre eliminación de todas las formas de discriminación contra la mujer (Memoria para optar al grado de licenciada en ciencias jurídicas, Universidad de Chile, Santiago, 1994); Binnstock, Hanna, Hacia la igualdad de la mujer. Avances legales desde la aprobación de la Convención sobre eliminación de todas las formas de discriminación contra la mujer, ob. cit. 
Partes un amplio espectro de posibilidades para adoptar medidas que apunten al fin señalado por esta norma. Por ello, desde la perspectiva de esta Convención, la implementación de medidas estatales tendientes a lograr una mejor conciliación de obligaciones laborales con responsabilidades familiares no deben ser solo de carácter jurídico laboral para producir efectos en las condiciones de empleo de trabajadoras y trabajadores, sino que pueden ser perfectamente de otra índole, en particular, políticas sociales de fomento del empleo y de capacitación o del ámbito de la seguridad social, que sin requerir de una consagración legal, puedan producir un cambio o repercutir positivamente en la situación laboral de trabajadoras y trabajadores con responsabilidades familiares. Por lo tanto, medidas que tiendan a facilitar, por ejemplo, que las personas de la tercera edad puedan tener asistencia médica y personal en centros especiales, contribuirían a que las personas de su familia que asumen su cuidado, a falta de otras instancias, puedan acceder al mercado de trabajo en igualdad de oportunidades que otras personas sin responsabilidades familiares. Lo mismo ocurriría, si se amplía la cobertura de establecimientos de educación preescolar, de tal manera que las madres puedan dejar en ellos a sus hijos mayores de dos años y que aún no están en edad escolar, lo que les facilitaría a éstas el desarrollo de alguna actividad remunerada durante ese tiempo.

Con lo expuesto se ha querido ilustrar que las posibilidades de dar pleno cumplimiento a las obligaciones y compromisos asumidos por Chile al ratificar esta Convención son variados y que no necesariamente suponen, en el marco de nuestro actual ordenamiento jurídico laboral, que se adopten reformas legales para alcanzar los fines perseguidos. Por tanto, se requiere más bien que la integración en igualdad de oportunidades de las personas con responsabilidades familiares al mercado laboral se constituya en un principio rector de las políticas sociales y laborales del Estado, como a su vez, que se incluya en acuerdos que suscriban los actores sociales en los procesos de negociación colectiva ${ }^{23}$ para lograr, en conjunto, un cambio que asegure en nuestro país la construcción de un mercado de trabajo más justo y solidario ${ }^{24}$.

${ }^{23}$ Véase: Abramo, Laís - Rangel, Marta (editoras), Negociación colectiva y equidad de género (Oficina Regional de la OIT para América Latina y el Caribe, Santiago, 2005), pp. 15 s.

${ }^{24}$ En igual sentido: Servicio Nacional de la Mujer, Análisis sobre experiencias en empresas sobre compatibilización de vida laboral y familiar, ob. cit., p. 6. 


\section{ACTUALES OPORTUNIDADES DE CONCILIACIÓN DE TRABAJO Y VIDA FAMILIAR RECONOCIDAS EN LA LEGISLACIÓN LABORAL CHILENA}

Antes de analizar las oportunidades de conciliación de trabajo y vida familiar que pueden establecerse a la luz del actual ordenamiento jurídico laboral, es importante tener en consideración que hoy en día en Chile las posibilidades reales de armonizar la vida laboral y familiar se ven dificultadas, pues los datos comparativos muestran que en el país se trabaja más horas al año que en muchos otros países ${ }^{25}$. A la luz de un estudio realizado por la Dirección del Trabajo ${ }^{26}$ hay factores en la intensidad y extensión de la jornada de trabajo que no constituyen una libre elección del trabajador, sino que están definidos por imposiciones externas derivadas de la necesidad de obtener mejores remuneraciones. Esta es la situación en la que se encuentra una gran cantidad de trabajadores, respecto de quienes el tipo de remuneración más importante son comisiones, trato o piezas. Para otros grupos de trabajadores, en cambio, la larga extensión de sus jornadas de trabajo se explica por la necesidad de mejorar las remuneraciones con la realización de horas extraordinarias y el trabajo en día domingo o por la necesidad de lograr metas de producción que involucran bonos o, simplemente, por la naturaleza de las faenas, que tienen momentos de alta intensidad. En este tipo de actividades, el esfuerzo individual pasa a ser la única forma de obtener el salario comprometido en la relación contractual. De esta manera, entonces, sucede que la intensidad y extensión de la jornada, coincide con actividades que requieren alto esfuerzo físico y que normalmente se realizan en ambientes donde los riesgos no son menores. Además, la extensión de la jornada de trabajo afecta a trabajadores que deben desarrollar sus actividades en ambientes muchas veces inhóspitos, si se considera que se debe permanecer dentro de ellos por largas jornadas y presionados por la obtención de comisiones, como es el caso de los trabajadores del comercio, quienes cuentan, a su vez, con escasas pausas en la jornada diaria y están aislados de sus familias durante dos días domingo en el mes y antes de festividades de enorme significación simbólica, tales como la Navidad o el año nuevo ${ }^{27}$.

En consecuencia, en el actual escenario que se presenta en el mercado

${ }^{25}$ La Dirección del Trabajo ha efectuado un interesante estudio sobre la materia, véase: Riquelme, Verónica, El tiempo de trabajo, en Temas Laborales 11 (enero 1999), disponible en www.dt.gob.cl.

${ }^{26}$ Espinoza, Malva, Calidad de vida en el trabajo: reflexiones en torno a la inseguridad y el malestar social, en Temas Laborales 18 (2001), disponible en www.dt.gob.cl.

${ }^{27}$ Riquelme, Verónica, El tiempo de trabajo, ob. cit. 
laboral nacional la principal demanda de los trabajadores chilenos, no es la de trabajar menos, por una actitud proclive al ocio, sino trabajar en mejores condiciones $^{28}$. Por lo anterior, reformas como la rebaja del límite de la jornada de trabajo ordinaria de 48 horas a 45 horas semanales ${ }^{29}$ constituyó una oportunidad para que las empresas chilenas comenzaran a planificar una racionalización de los tiempos de trabajo y una mejor distribución de las capacidades productivas y de los rendimientos esperados para cada trabajador. Lamentablemente, de acuerdo a lo establecido por la Dirección del Trabajo ${ }^{30}$ hay pocos ejemplos sobre esta materia, pero sin duda serán las empresas innovadoras, las que tendrán una ventaja sobre las empresas que insistan en quedarse apegadas a esquemas rígidos, ya que éstos lejos de mostrar eficiencia productiva, generan una baja calidad de vida en el trabajo que se extiende a la calidad de la vida privada, en la medida que no queda tiempo para la familia, el desarrollo individual, la capacitación, la creatividad, el descanso, la recreación, la participación ciudadana y todos los supuestos roles que demanda en teoría una sociedad moderna.

Sin perjuicio de lo anterior, cabe tener en cuenta que contribuye a valorizar a la necesidad de un estudio sobre el tema el hecho que recientes modificaciones legales introducidas al Código del Trabajo, como es el caso de las Leyes No 20.047, 20.137 y 20.166, han tendido a reconocer nuevos derechos tanto a padres y madres trabajadores en lo que respecta a su aspiración por armonizar su vida laboral y familiar, lo que amerita un análisis integrado de estas reformas. A su vez, se debe considerar que en los últimos años Chile ha ratificado importantes instrumentos internacionales sobre materias referidas a la prohibición de discriminación en el empleo y, por ende, destinadas a garantizar la igualdad de oportunidades laborales entre hombres y mujeres, lo que conlleva la necesidad de establecer si nuestro país está cumpliendo cabalmente las obligaciones que ha asumido, sobre todo, porque muchos de estos acuerdos supranacionales se vinculan con el debido respeto de derechos humanos fundamentales ${ }^{31}$.

A continuación, se examinarán de acuerdo a su actual regulación en el ст., diversos derechos que se les reconocen a los padres trabajadores y que tienen una incidencia directa en la concreción de oportunidades de

${ }^{28}$ Espinoza, Malva, Calidad de vida en el trabajo: reflexiones en torno a la inseguridad y el malestar social, ob. cit..

${ }^{29}$ Reforma introducida al artículo $22 \mathrm{CT}$. por la Ley $\mathrm{N}^{\circ} 19.759$, publicada en el Diario Oficial de fecha 5 de octubre de 2001.

${ }^{30}$ Espinoza, Malva, Calidad de vida en el trabajo: reflexiones en torno a la inseguridad y el malestar social, ob. cit..

${ }^{31}$ Véase: CAAmaño, Eduardo, El derecho a la no discriminación en el empleo (Santiago, 2005). 
armonización de trabajo y vida familiar. Luego, en el acápite siguiente, se efectuará un juicio de crítico de todos ellos, en vistas a establecer los aspectos positivos y las deficiencias que presenta el ordenamiento jurídico laboral para adecuarse a esta nueva aspiración del Derecho del Trabajo de obtener un resguardo de los derechos de los trabajadores, en concordancia con sus responsabilidades familiares, bajo el entendido que una mejor calidad de vida en el trabajo contribuye directamente a aumentar la productividad de las empresas y a materializar la eficacia del derecho a la igualdad de oportunidades entre hombres y mujeres en el empleo.

\section{Descanso maternal.}

El derecho al descanso prenatal y postnatal constituye uno de los primeros beneficios especiales que la normativa laboral internacional estableció a favor de la madre trabajadora, pues ya el primer Convenio No 3 de la OIT sobre protección a la maternidad de 1919 reconoció el descanso antes y después del parto, en vistas a permitir un buen término del embarazo, protegiendo así al hijo y a la madre, como a su vez, con el fin de asegurar un tiempo mínimo para que luego del parto la madre le pueda dedicar todos sus cuidados al hijo recién nacido antes de reintegrarse a su trabajo. Con posterioridad, los nuevos convenios de la ort sobre la materia, el No 103 de 1952 y el No 183 de 2000, han reforzado este derecho y ampliado el grupo de las mujeres beneficiarias de estas normas protectoras.

En nuestro país, ya las primeras leyes laborales del año 1924 consagraron este derecho, aunque en términos bastante más restringidos, para ir ampliándolo en la posterior normativa laboral, particularmente, en el Código del Trabajo de 1931 y en las versiones posteriores de este cuerpo normativo, hasta llegar a su actual consagración en el artículo 195 Ст., el cual prescribe que: "Las trabajadoras tendrán derecho a un descanso de maternidad de seis semanas antes del parto y doce semanas después de él".

Para que la trabajadora pueda hacer uso del descanso de maternidad previo al parto es necesario, según el artículo 197 СT., que presente al empleador un certificado médico o de matrona que acredite que el estado de embarazo ha llegado al período fijado para obtenerlo, para lo cual el legislador ha dispuesto que estos certificados deben ser expedidos gratuitamente por los médicos o matronas que por cualquier concepto perciban remuneraciones de Estado. Por su parte, en lo que respecta al permiso postnatal, cabe señalar que éste comienza con el hecho del parto según lo señalado por el inciso $1^{\circ}$ del artículo 195 Cт., por lo que, en definitiva, el parto viene a constituir el requisito sine qua non para su ejercicio. Sin perjuicio de ello, debe hacerse presente que el Código no condiciona el nacimiento de este derecho a la circunstancia de que la criatura nazca viva, 
ni exige para su continuidad que el nińo sobreviva con posterioridad al parto ${ }^{32}$.

Finalmente, en relación con el derecho básico al descanso prenatal y postnatal es digno de destacarse que la Dirección del Trabajo ${ }^{33}$ ha constatado que se trata de un derecho altamente respetado, lo que se explica por la legitimidad de que goza y por el financiamiento estatal que tiene ${ }^{34}$. Sin embargo, es un derecho que se ha comenzado a discutir en lo que se refiere a su extensión, con la finalidad de flexibilizar el tiempo del descanso prenatal, permitiendo que la trabajadora embarazada pueda postergar el inicio del descanso, si su salud lo permite, y trasladar los días no utilizados al tiempo de descanso postnatal, para extender así su duración, pues tiende a ser considerado como insuficiente para satisfacer los deseos de la madre trabajadora de proporcionar cuidados personales a su hijo recién nacido durante un mayor período antes de retornar a su empleo ${ }^{35}$.

\section{Descanso paternal.}

El actual artículo 195 inciso $2^{\circ}$ ст., dispone que: "El padre tendrá derecho a un permiso pagado de cinco días en caso de nacimiento de un hijo, el que podrá utilizar a su elección desde el momento del parto, y en este caso será de días corridos, o distribuirlo dentro del primer mes desde la fecha del nacimiento. Este permiso también se otorgará al padre que se le conceda la adopción de un hijo, contado desde la respectiva sentencia definitiva. Este derecho es irrenunciable ${ }^{36}$.

Esta disposición es sin lugar a dudas uno de los más notables avances

${ }^{32}$ Así lo ha reconocido también la Dirección del Trabajo en el dictamen № 3143, de fecha 27 de mayo de 1985.

${ }^{33}$ Henríquez, Helia - Riquelme, Verónica - Cárdenas, Tatiana, Las normas que protegen la maternidad en Chile: el comportamiento de las empresas, en Cuadernos de Investigación 3 (mayo 1997), pp. 45 s.

${ }^{34}$ En efecto, el artículo 198 CT. dispone que: "La mujer que se encuentre en el periodo de descanso de maternidad a que se refiere el artículo 195, o de descansos suplementarios $y$ de plazo ampliado señalados en el artículo 196, recibirá un subsidio equivalente a la totalidad de las remuneraciones y asignaciones que perciba, del cual sólo se deducirán las imposiciones de previsión y descuentos legales que correspondan”. El cálculo y otorgamiento de este subsidio se determina conforme a las disposiciones del Decreto Supremo No 210 del Ministerio del Trabajo y Previsión Social, publicado en el Diario Oficial de fecha 17 de junio de 1986.

${ }^{35}$ En este sentido se ha planteado el tema por el proyecto de ley que establece normas para flexibilizar el uso del permiso maternal (Boletín No 1309-13, ingresado a tramitación con fecha 4 de agosto de 1994), que actualmente se encuentra en su segundo trámite constitucional.

${ }^{36}$ Esta disposición fue incorporada al Código del Trabajo por la Ley $\mathrm{N}^{\circ} 20.047$, publicada en el Diario Oficial de fecha 2 de septiembre de 2005. 
que ha experimentado la protección legal a la maternidad en el último tiempo, pues viene a incluir explícitamente al padre como beneficiario de un derecho derivado del nacimiento de un hijo, con lo cual nuestro actual ordenamiento jurídico comienza a apartarse de aquel arquetipo social ya mencionado precedentemente, en virtud del cual le corresponde en forma casi exclusiva a la madre el cuidado de los hijos, limitándose el rol del padre al de proveedor y trabajador a tiempo completo ${ }^{37}$. Con esta reforma legal, entonces, se reconoce expresamente que el padre trabajador también tiene derechos como tal y que debe tener la posibilidad de asumir su responsabilidad frente al nacimiento de un hijo, en un momento particularmente sensible, como es el primer mes de vida de un niño, período en el cual el menor requiere una enorme cantidad de cuidados que no pueden quedar entregados sólo a la madre. Lo anterior explica también la opción del legislador para que este permiso sea utilizado, preferentemente ${ }^{38}$, dentro de los 5 días siguientes al parto, o bien, en forma discontinua dentro del primer mes desde la fecha del nacimiento.

Por otra parte, cabe destacar que el permiso que se le reconoce al padre es pagado, lo que implica que conserva su derecho a percibir remuneraciones íntegras durante el tiempo en el cual haga uso de él, con lo cual se persigue asegurar que el ejercicio de este beneficio no suponga un detrimento a su situación laboral o que origine la necesidad posterior de compensar el tiempo no trabajado, lo que terminaría afectando la efectividad del permiso $^{39}$. Con todo, si bien esta garantía es beneficiosa para el trabajador, cabe preguntarse por qué los costos de ella deben ser asumidos exclusivamente por el empleador, en circunstancias que el nacimiento de un hijo en último término implica un beneficio para el país, particularmente, en un contexto como el actual con una fuerte tendencia a la disminución de la natalidad ${ }^{40}$. Lo anterior puede explicarse como una consecuencia del hecho que el actual ordenamiento jurídico laboral sigue operando en base al supuesto

${ }^{37}$ Sobre el permiso paternal en el derecho comparado: Tortuero, José Luis, 50 propuestas para racionalizar la maternidad y facilitar la conciliación laboral, ob. cit., pp. $103 \mathrm{~s}$.

${ }^{38}$ Esta opción puede entenderse como preferente, ya que es la primera que se menciona y porque está más en concordancia con el espíritu de la reforma, cual es que el padre participe activamente en el nacimiento de su hijo y esté junto a la madre en los primeros días que exigen una mayor atención del menor, sobre todo si se considera que la madre está comenzando a recuperarse del parto.

${ }^{39}$ Véase el dictamen de la Dirección del Trabajo $N^{\circ}$ 3827/103, de fecha 2 de septiembre de 2005, que fija el sentido y alcance del artículo 195 inciso $2^{\circ} \mathrm{CT}$.

${ }^{40}$ Véase: Instituto Nacional de Estadísticas, La fecundidad en Chile. Situación reciente, noviembre 2006, disponible en: www.ine.cl/canales/chile_estadistico/demografia_y_vitales/demografia/pdf/fecundidad.pdf. 
de una distribución clásica de roles laborales y paternales, como a su vez, desconociendo que una adecuada conciliación de trabajo y vida familiar es un tema de interés general y no exclusivamente de interés de los padres, por lo que es cuestionable la mantención de un modelo normativo que tiende a asignar el costo del reconocimiento de estos derechos sólo al empleador, sin que se cuestione técnicamente el impacto en los costos laborales directos e indirectos que beneficios como éste tienen en el mercado de trabajo y en su validación social por parte del empresariado.

Sin perjuicio de lo ya señalado, es importante hacer presente que la Dirección del Trabajo ${ }^{41}$ en relación con este permiso ha resuelto que, a elección del padre, podrá utilizarse desde el momento del parto, y en este evento, por expreso mandato del legislador, los cinco días que éste comprende deberán impetrarse en forma continua, esto es, sin interrupciones, salvo las que derivan de la existencia de días de descanso semanal, que pudieran incidir en el período. Si el padre no opta por esta alternativa, podrá hacer uso de los cinco días de permiso dentro del primer mes desde la fecha de nacimiento, estando facultado para distribuirlos como estime conveniente, sea en forma continua o fraccionada. De igual manera, este Servicio en base a los antecedentes de la historia de la Ley $N^{\circ} 20.047$ ha establecido que el permiso no se aumenta en caso de nacimientos o partos múltiples, lo que implica que el padre sólo tendrá derecho a cinco días por tal causa, cualquiera que sea el número de hijos producto del embarazo.

Para concluir, es digno de destacarse que el nuevo texto del artículo 195 inciso $2^{\circ}$ Ст. ha incluido también como beneficiario de este derecho al padre adoptivo, con lo cual la actual normativa sobre protección a la maternidad ha continuado avanzando en torno a la igualación de los derechos entre padres trabajadores biológicos y adoptivos, lo que representa a todas luces un importante incentivo para promover la adopción en el país. Por tanto, el padre a quien se le conceda la adopción de un hijo tiene derecho a impetrar cinco días de permiso pagado por tal causa, beneficio que deberá hacerse efectivo a contar de la fecha de la respectiva sentencia definitiva ${ }^{42}$.

\section{Derecho a sala cuna.}

A diferencia de otros derechos comprendidos dentro de la protección a

${ }^{41}$ Dictamen de la Dirección del Trabajo $N^{\circ} 3827 / 103$, de fecha 2 de septiembre de 2005.

${ }^{42}$ En detalle: Reveco, Carla, Normas de protección a la maternidad en el derecho del trabajo y su aplicación respecto de los padres adoptivos (Memoria para optar al grado de licenciada en ciencias jurídicas, Pontificia Universidad Católica de Valparaíso, Valparaíso, 2005). 
la maternidad en el Ст., el derecho a la sala cuna se caracteriza por no ser de aplicación general. Esto se explica, porque no siempre la trabajadora tendrá este derecho, toda vez que ello sólo es posible si concurran los requisitos legales que hacen surgir para el empleador la correspondiente obligación de mantener o pagar una sala cuna para que los hijos de las trabajadoras puedan ser cuidados mientras sus madres cumplen sus prestaciones laborales.

El artículo 203 ст. es la disposición que se ocupa sobre las salas cunas y establece en su inciso $1^{\circ}$ que: "Las empresas que ocupan veinte o más trabajadoras de cualquier edad o estado civil, deberán tener salas anexas e independientes del local de trabajo, en donde las mujeres puedan dar alimento a sus hijos menores de dos años y dejarlos mientras estén en el trabajo. Igual obligación corresponderá a los centros o complejos comerciales e industriales $y$ de servicios administrados bajo una misma razón social o personalidad jurídica, cuyos establecimientos ocupen entre todos, veinte o más trabajadoras. El mayor gasto que signifique la sala cuna se entenderá común y deberán concurrir a él todos los establecimientos en la misma proporción de los demás gastos de ese carácter".

En su esencia, esta disposición está inspirada en la idea de que la sociedad y la empresa deben garantizar la compatibilidad entre el trabajo que realizan las mujeres y la maternidad. Si bien la mayor parte de los costos de la maternidad recaen sobre el sistema de seguridad social y sobre el Estado, el cuidado de los hijos de las trabajadoras se entregó a las empresas, pero no se responsabilizó a todo el empresariado sino que exclusivamente a los empleadores de mujeres. Es así, entonces, como de acuerdo a la disposición antes transcrita el nacimiento de la obligación del empleador de otorgar sala cuna presupone el cumplimento de los siguientes requisitos copulativos:

i) De acuerdo a lo dispuesto por el artículo 203 ст., la obligación de mantener o financiar salas cunas está dirigida a toda empresa, como asimismo, a los centros o complejos comerciales e industriales y de servicios administrados bajo una misma razón social o personalidad jurídica ${ }^{43}$.

${ }^{43}$ Debe tenerse en consideración que en virtud de la reforma introducida por la Ley No 19.591, ya no se restringe la obligación de mantener sala cuna al establecimiento, lo que se prestaba a prácticas bastante cuestionables de ciertos empleadores para evitar el otorgamiento de este derecho a sus trabajadoras, sino que se extiende a la empresa, con lo cual, se hizo posible ampliar el espectro de sujetos obligados a mantener salas cunas en beneficio de sus trabajadoras, en la medida, claro está, que se cumpla también con el requisito referido al número de trabajadoras que debe ocupar la empresa. Por otra parte, merece señalarse que la Ley No 19.408 extiende la obligación de mantener salas cunas a los centros o complejos comerciales, en vistas a otorgarle 
ii) La empresa debe ocupar a veinte o más trabajadoras de cualquier edad o estado civil. Para los efectos de contabilizar su número es irrelevante el tipo o naturaleza de los contratos de trabajo ${ }^{44}$, por lo que serán contadas de igual forma las trabajadoras con contrato de duración indefinida que las trabajadoras con contrato de duración determinada, como asimismo, las trabajadoras a tiempo completo y aquellas contratadas a tiempo parcial ${ }^{45}$. A su vez, como lo señala expresamente esta disposición es irrelevante el estado civil de las trabajadoras ${ }^{46}$ para los efectos del cómputo del número mínimo de trabajadoras que debe ocupar una empresa, para que deba otorgarse el beneficio de la sala cuna ${ }^{47}$.

Con todo, como lo ha reconocido la Dirección del Trabajo, la vinculación que introduce el artículo 203 ст. con un número determinado de trabajadoras, como presupuesto para el nacimiento del derecho a la sala cuna, trae aparejado como consecuencia que si el número de mujeres en la empresa es inferior a veinte -situación generalizada en las PYME que representan el porcentaje mayor de empresas en el país ${ }^{48}$ - no existe este derecho, como a su vez, éste cesa, si el número de trabajadoras disminuye a menos de veinte, sin perjuicio del derecho adquirido de aquellas que ya

este derecho a una gran cantidad de trabajadoras que prestan servicios en el sector del comercio, siendo digno de destacarse que el legislador, con un criterio solidario, ha dispuesto en estos casos que la obligación debe cumplirse de forma comunitaria entre los distintos establecimientos comerciales del centro o complejo, para lo cual el gasto que conlleva la mantención de la sala cuna es considerado como común y, por lo tanto, se prorratea entre éstos en la misma proporción que los demás gastos comunes. Con todo, es requisito especial en estos casos, que el centro o complejo esté administrados bajo una misma razón social o personalidad jurídica. Sobre la materia, véase los dictámenes de la Dirección del Trabajo No 2265/86, de fecha 15 de abril de 1996 y No 8086/326, de 18 de diciembre de 1995.

${ }^{44}$ Así lo ha establecido la Dirección del Trabajo en el dictamen No 3158/114, de fecha 24 de abril de 1987.

${ }^{45}$ Sobre el derecho a sala cuna de las trabajadoras a tiempo parcial véase el dictamen de la Dirección del Trabajo $N^{\circ}$ 1716/066, de fecha 18 de marzo de 1996.

${ }^{46}$ Ver dictamen de la Dirección del Trabajo No 633/51, de fecha 11 de febrero de 1993.

${ }^{47}$ Respecto de los centros o complejos comerciales e industriales y de servicios administrados bajo una misma razón social o personalidad jurídica, el número de 20 trabajadoras debe compatibilizarse de forma común y no por separado, con lo que se ha logrado extender este derecho a una gran cantidad de trabajadoras que en virtud del primitivo texto de esta disposición legal quedaban excluidas del beneficio de la sala cuna.

${ }^{48}$ En el presente se estudia en el Congreso Nacional un proyecto de ley que pretende extender el derecho a sala cuna a todos los trabajadores. Esta iniciativa tiene por objeto modificar el Código del Trabajo, a fin de otorgar el beneficio de sala cuna a todas las mujeres trabajadoras, sea cual fuere el número de ellas dentro de la empresa. 
estaban haciendo uso de él, al momento de producirse la disminución de trabajadoras en la empresa ${ }^{49}$.

Esta situación derivada de la necesaria concurrencia de ambos requisitos para el nacimiento del derecho a sala cuna no deja de ser problemática, puesto que restringe efectivamente el goce de un derecho que es de vital importancia para las madres trabajadoras al permitirles conciliar efectivamente el trabajo con sus responsabilidades familiares y, por consiguiente, tener una verdadera igualdad de oportunidades con los hombres en el mercado laboral. Además, el límite legal impuesto al ejercicio del derecho a sala cuna se presta a conductas reñidas con la ética por parte de ciertos empleadores, quienes se valen de subterfugios o medidas organizativas dudosas (v. gr. ocupar un máximo de 19 trabajadoras) para evitar el tener que estar en la situación de verse obligados a mantener o pagar sala cuna a los hijos de sus trabajadoras.

En lo que respecta a la forma en que el empleador debe cumplir la obligación impuesta por el artículo 203 CT., en el evento que concurran los requisitos legales recién mencionados, esta misma disposición ha prescrito que ello puede hacerse de tres formas:

i) manteniendo el empleador salas anexas e independientes del lugar de trabajo, en donde las mujeres puedan dar alimento a sus hijos y dejarlos mientras están en el trabajo; o

ii) creando y manteniendo salas cunas en común con otros establecimientos de empresas obligadas o con otros centros o complejos, según sea el caso, que estén ubicados en la misma zona geográfica ${ }^{50}$, previo informe favorable de la Junta Nacional de Jardines Infantiles; o bien

iii) pagando los gastos de sala cuna directamente al establecimiento al que las trabajadoras lleven a sus hijos menores de 2 años. En este caso, el empleador designará la sala cuna, de aquellas que cuenten con la autorización de la Junta Nacional de Jardines Infantiles. Además, en este caso, el empleador debe pagar también los gastos de locomoción en que incurra la trabajadora para ir a dejar y a buscar a su hijo menor de 2 ańos y para ir a darle alimento.

Conforme con lo anterior el empleador no podría dar por satisfecha la obligación relativa a la sala cuna mediante el procedimiento de entregar directamente a la mujer una suma de dinero, supuestamente equivalente

${ }^{49}$ Así lo ha resuelto la Dirección del Trabajo en el dictamen No 1629/100, de fecha 29 de mayo del 2002.

${ }^{50}$ Según el estudio de la Dirección del Trabajo, esta modalidad de cumplir la obligación de mantener sala cuna no ha sido utilizada nunca, pese a sus ventajas de costo. Ver: Henríquez, Helia - Riquelme, Verónica - Cárdenas, Tatiana, Las normas que protegen la maternidad en Chile: el comportamiento de las empresas, ob. cit., pp. $58 \mathrm{~s}$. 
a los gastos que irrogaría la atención del menor en la sala cuna ${ }^{51}$. A mayor abundamiento, cabe agregar que el pago directo a la trabajadora de una suma de dinero para solventar los gastos de sala cuna implicaría según la Dirección del Trabajo una renuncia a un derecho laboral por parte de ésta, lo que de acuerdo al artículo 5 inciso $2^{\circ}$ CT., se encuentra prohibido en tanto se mantenga vigente la relación laboral. No obstante, la interpretación anterior puede ser cuestionada, pues excluye en base a una mera interpretación literal y desconociendo el fin protector de la norma, una alternativa que ha comenzado a generar bastante interés tanto a las trabajadoras como a los mismos empleadores por las ventajas prácticas que presenta (v. gr.,. menores posibilidades de que los hijos contraigan enfermedades o el ahorro de gastos de traslado) y que, en la medida que no implique restricciones al ejercicio de este derecho puede promover una adecuada armonización de trabajo y vida familiar.

Finalmente, cabe hacer presente que conforme al artículo 203 inciso $1^{\circ}$ CT. el derecho de la madre trabajadora de llevar su hijo a la sala está limitado en razón de la edad del menor, puesto que se extiende sólo hasta que el niño cumpla 2 años de edad ${ }^{52}$.

\section{Derecho a dar alimentos.}

De conformidad a lo prescrito por el nuevo texto del artículo 206 СT., luego de la modificación introducida por la Ley No 20.166 33 : “(inciso 1) Las trabajadoras tendrán derecho a disponer, a lo menos, de una hora al dia, para dar alimento a sus hijos menores de dos años. Este derecho podrá ejercerse de alguna de las siguientes formas a acordar con el empleador:/ a) En cualquier momento dentro de la jornada de trabajo./b) Dividiéndolo, a solicitud de la interesada, en dos porciones. (c) Postergando o adelantando en media hora, o en una hora, el inicio o el término de la jornada de trabajo".

En relación con la norma citada es interesante señalar que su nuevo texto responde a la satisfacción de una necesidad planteada hace bastante tiempo en torno a las formas en que se podía hacer uso de este importante derecho, toda vez que el anterior texto del artículo 206 partía del supuesto de su ejercicio durante la jornada de trabajo, no quedando clara la procedencia de alternativas diferentes de distribución de este tiempo, a pesar de que en la práctica se utilizaban generalizadamente variantes como el retraso de la

${ }^{51}$ Dirección del Trabajo, dictamen No 620/37 de fecha 5 de febrero de 1997. En igual sentido, dictamen No 5831 de fecha 10 de diciembre de 1984 y No 8365/252 de fecha 17 de noviembre de 1987.

${ }^{52}$ Así lo ha entendido también la Dirección del Trabajo en el Dictamen No 7486/171, de fecha 19 de octubre de 1990.

${ }^{53}$ Publicada en el Diario Oficial de fecha 12 de febrero de 2007. 
hora de ingreso o el adelanto de la hora de salida hasta en una hora. Con el nuevo texto, quedan claras las distintas alternativas de uso, quedando a criterio de la madre trabajadora su elección, con lo cual se favorece que ésta pueda asumir de mejor manera sus responsabilidades familiares.

Sin perjuicio de lo anterior, lo más destacable de esta reforma es que el nuevo texto del artículo 206 en su inciso $2^{\circ}$ permite que este derecho pueda ser ejercido preferentemente en la sala cuna, o en el lugar en que se encuentre el menor, con lo cual se zanjó definitivamente una larga controversia interpretativa, pues la Dirección del Trabajo ${ }^{54}$ reiteradamente sostenía que el derecho a dar alimentos sólo procedía si la trabajadora tenía derecho a sala cuna y, como se estableciera en el punto precedente, ello sólo tenía lugar si la empresa ocupaba más de veinte trabajadoras, con lo que en los hechos se privaba a una gran cantidad de trabajadoras de toda posibilidad de dar alimentos a sus hijos ${ }^{55}$. Con el texto actual, toda trabajadora, tenga o no derecho a sala cuna podrá disponer de una hora al día, a lo menos, para los efectos de poder dar alimento a sus hijos, por lo que se ha dado un paso importante hacia una conciliación más efectiva de trabajo y vida familiar. Destaca, además, que la nueva disposición reitera una regla del antiguo texto, en cuanto que para todos los efectos legales, el tiempo utilizado en el ejercicio de este derecho se considerará como trabajado.

Reforzando lo anterior, el inciso $4^{\circ}$ del artículo 206 ст. dispone que: " $E l$ derecho a alimentar consagrado en el inciso primero, no podrá ser renunciado en forma alguna y le será aplicable a toda trabajadora que tenga hijos menores de dos años, aun cuando no goce del derecho a sala cuna, según lo preceptuado en el artículo 203". La única diferencia entre trabajadoras con y sin derecho a sala cuna es que, tratándose de empresas que estén obligadas otorgar sala cuna, el período de tiempo destinado a dar alimentos se ampliará al necesario para el viaje de ida y vuelta de la madre para dar alimentos a sus hijos. En este caso, el empleador pagará el valor de los pasajes por el transporte que deba emplearse para la ida y regreso de la madre.

${ }^{54}$ Entre otros: dictamen No 7486/171, de fecha 19 de octubre de 1990; dictamen No 2615/124, de fecha 2 de mayo de 1994; dictamen No 4201/194, de fecha 19 de julio de 1994; dictamen No 4360/238, de fecha 24 de julio de 1997.

${ }^{55}$ Para fundamentar la posición anterior, la Dirección del Trabajo recurría reiteradamente al argumento que "el artículo 206 CT. es complementario de lo preceptuado en el articulo 203 del mismo cuerpo legal, determinando la forma de aplicar o hacer efectivo el derecho a dar alimento a los hijos que la última de las disposiciones nombradas confiere a las trabajadoras que concurran a la sala cuna, razón por la cual debe entenderse exigible sólo en la medida que las empresas estén obligadas a mantener dicha sala cuna". En este sentido: dictamen No 4360/238 de fecha 24 de julio de 1997. 
Por último, cabe señalar que el objeto de este derecho, esto es, dar alimento ha sido interpretado en forma amplia por la Dirección del Trabajo ${ }^{56}$ y, por lo tanto, no puede entenderse restringido sólo al amamantamiento, como lo establecía el Código del Trabajo de 1931, sino que comprende cualquier alimento, con lo cual se busca reforzar el contacto entre madre e hijo y asegurar las posibilidades de que los hijos menores de dos años ${ }^{57}$ reciban atenciones y cuidados directos de su madre, lo que contribuye naturalmente a su sano y normal desarrollo.

\section{Permisos especiales.}

El Código del Trabajo, en sus artículos 199 y 199 bis, establece un sistema especial de permisos para los casos en que se produzca enfermedad del hijo menor de edad, siendo digno de destacarse que, haciendo excepción al criterio general de circunscribir la protección frente al nacimiento y cuidado de los hijos sólo a la madre, el legislador laboral ha introducido un mecanismo que acrecienta la participación del padre, permitiéndole también en ciertas situaciones hacer uso de estos permisos. Con medidas de este tipo se avanza hacia una nueva concepción de familia, en la que desde el punto de vista del trabajo se revaloriza la igualdad de hombres y mujeres en cuanto a su responsabilidad y participación en el cuidado de los hijos, lo que, en definitiva, asegura que ambos puedan -al menos en el plano teórico- contar con igualdad de oportunidades en el trabajo. No obstante, las posibilidades que se le reconocen al padre en esta materia siguen siendo limitadas y de escasa aplicación práctica, por lo que en el futuro debería plantearse un fortalecimiento de su rol frente a los hijos, en vistas a concretar una necesaria conciliación de trabajo y vida familiar.

El artículo 199 ст. se refiere al permiso frente a la enfermedad grave de un niño menor de un año y al respecto prescribe que: "Cuando la salud de un niño menor de un año requiera de atención en el hogar con motivo de enfermedad grave, circunstancia que deberá ser acreditada mediante certificado médico otorgado o ratificado por los servicios que tengan a su cargo la atención médica de los menores, la madre trabajadora tendrá derecho al permiso y subsidio que establece el articulo anterior (subsidio por maternidad) por el

${ }^{56}$ Dictamen No 7486/171, de la Dirección del Trabajo, de 19 de octubre de 1990.

${ }^{57}$ Sobre la extensión del derecho a dar alimentos respecto de madres con más de un hijo menor de 2 ańos o en los casos de partos múltiples véase: dictamen de la Dirección del Trabajo No 3362/102, de fecha 20 de agosto de 2003; CaAmaño, Eduardo, Comentarios en torno al nuevo dictamen de la Dirección del Trabajo sobre la extensión temporal del derecho a dar alimentos, en Revista Laboral Chilena 122 (diciembre 2003), pp. 73 s. 
periodo que el respectivo servicio determine. En el caso que ambos padres sean trabajadores, cualquiera de ellos y a elección de la madre, podrá gozar del permiso y subsidio referidos. Con todo, gozará de ellos el padre, cuando la madre hubiere fallecido o él tuviere la tuición del menor por sentencia judicial's8.

En resumen, este especial tipo de permiso requiere para poder ser ejercido que se produzca una enfermedad grave de un menor de un año de edad, que requiera atención en el hogar, y que esta enfermedad se acredite mediante el correspondiente certificado médico. En lo que se refiere a la duración del permiso y del correspondiente subsidio, ésta estará determinada por lo que especifique el servicio médico tratante, no siendo posible que el empleador se oponga a su otorgamiento. Por lo anterior, se robustece la responsabilidad de los trabajadores frente al adecuado uso de este beneficio y ello explica que el inciso final del artículo 199 Ст. disponga que: "Si los beneficios precedentes fueren obtenidos en forma indebida, los trabajadores involucrados serán solidariamente responsables de la restitución de las prestaciones pecuniarias percibidas, sin perjuicio de las sanciones penales que por este hecho les pudiere corresponder' 59 .

Por su parte, el artículo 199 bis Ст. consagra un permiso en caso de enfermedad de un menor de 18 años y dispone que: "Cuando la salud de un menor de 18 años requiera la atención personal de sus padres con motivo de un accidente grave o de una enfermedad terminal en su fase final o enfermedad grave, aguda y con probable riesgo de muerte, la madre trabajadora tendrá derecho a un permiso para ausentarse de su trabajo por el número de horas equivalentes a diez jornadas ordinarias de trabajo al año, distribuidas

${ }^{58}$ La Superintendencia de Seguridad Social en el dictamen No 11731, de fecha 3 de noviembre de 1995, ha resuelto que la circunstancia de que la trabajadora sólo hubiese tenido o tenga derecho al permiso, sin generar el subsidio respectivo por no reunir los requisitos de afiliación y cotización a que se refieren el artículo 4 del DFL No 44 de 1978 o el artículo 18 de la Ley No 18.469, según hubiese tenido o tenga la calidad de trabajadora dependiente o independiente, no impide que el padre o cónyuge, en su caso, puedan hacer uso de los permisos de que tratan los incisos 1 y 2 del artículo 199 CT., cuando la madre o la trabajadora que tiene bajo su cuidado al menor, opten porque dicho derecho sea utilizado por éstos, opción que no puede verse limitada por tal circunstancia, pudiendo el padre o cónyuge gozar de los permisos y de los subsidios por incapacidad laboral en su caso, si reúne los requisitos para ello.

${ }^{59}$ Las sanciones penales que podrían tener cabida, dependerán naturalmente de los hechos delictivos que se configuren, y podrán ser las derivadas de los artículos 193 a 198 del Código Penal (delitos de falsificación de documento público o auténtico) o la contenida en el artículo 205 del Código Penal, en caso de falsificación de certificado. En este sentido, Zamorano, Pilar, Descansos, subsidios e inamovilidad laboral por causa de maternidad (Memoria de prueba para optar al grado de licenciada en ciencias jurídicas, Universidad de Chile, Santiago, 2000), p. 59. 
a elección de ella en jornadas completas, parciales o combinación de ambas, las que se considerarán como trabajadas para todos los efectos legales. Dichas circunstancias del accidente o enfermedad deberán ser acreditadas mediante certificado otorgado por el médico que tenga a su cargo la atención del menor". A su vez, el inciso $2^{\circ}$ permite que también el padre pueda ser uso de este permiso, con derecho a remuneraciones, en el evento que éste sea también un trabajador, caso en el cual, la decisión de que éste pueda hacer uso de este beneficio queda entregada a la madre. Además, este permiso se otorgará también al padre que tuviere la tuición del menor por sentencia judicial o cuando la madre hubiere fallecido o estuviese imposibilitada de hacer uso de él por cualquier causa o, a falta de ambos, a quien acredite su tuición o cuidado.

Si bien el Código del Trabajo confiere este permiso especial con derecho a mantener las remuneraciones durante el tiempo no trabajado, no se reconoce una liberación plena de la obligación de la trabajadora o del trabajador de prestar sus servicios de conformidad al contrato, toda vez que el tiempo que comprende el permiso deberá ser restituido, según lo dispone el artículo 199 bis inciso $3^{\circ}$. Las formas de efectuar esta restitución del tiempo no trabajado son: imputando las horas no trabajadas al feriado anual; laborando horas extraordinarias ${ }^{60}$ o por cualquier forma que convengan libremente las partes ${ }^{61}$. Si no resulta posible la aplicación de los mecanismos anteriores, el inciso $4^{\circ}$ de esta norma seńala que se podrá descontar el tiempo equivalente al permiso obtenido de las remuneraciones mensuales del trabajador, en forma de un día por mes, lo que podrá fraccionarse según sea el sistema de pago, o en forma íntegra si el trabajador cesare en su trabajo por cualquier causa.

Para concluir este acápite, merece un comentario la limitación impuesta por el legislador para la procedencia de este permiso en el artículo 199 bis, pues la posibilidad de hacer uso de este beneficio está restringida a situaciones extremas, tales como accidentes graves o enfermedades terminales que pudieran afectar al hijo, lo que impide que este permiso de tanta significación para los padres pueda utilizarse también para otras enfermedades graves, pero que no revistan la gravedad extrema aludida.

${ }^{60}$ En este caso, el tiempo trabajado por sobre la jornada ordinaria diaria no se pagará con recargo, de conformidad con lo previsto por el artículo 32 inciso $4^{\circ} \mathrm{CT}$., pues se trata de la compensación de un permiso.

${ }^{61}$ En los casos de trabajadores regidos por estatutos, el inciso 3 del artículo 199 bis CT. señala que si los estatutos contemplan la concesión de días administrativos, primeramente el trabajador deberá hacer uso de ellos, luego podrá imputar el tiempo que debe reponer a su próximo feriado anual o a días administrativos del año siguiente al uso del permiso a que se refiere este artículo, o a horas extraordinarias. 
Por ello, en aras de promover una mayor intervención de los padres en el cuidado de los hijos sería deseable la ampliación de este permiso (v. gr., a través de acuerdo colectivos) también para enfermedades menos graves y fortalecer el papel del padre frente al cuidado de sus hijos, sin perjuicio que el mecanismo de restitución del tiempo que comprende los permisos parece una opción adecuada para compatibilizar los intereses de los padres trabajadores y de los empleadores.

\section{TEMAS PENDIENTES}

Del examen de las diversas alternativas de conciliación de trabajo y familia que pueden establecerse conforme al actual ordenamiento jurídico laboral, cabe señalar, en primer lugar, que sus ventajas desde la perspectiva del tema en análisis son más bien accidentales, pues los diversos derechos analizados constituyen en esencia garantías tendientes a asegurar la protección a la maternidad. En efecto, cada uno de los derechos analizados está regulado en el Código del Trabajo, en el título $2^{\circ}$ de su libro II sobre protección a la maternidad y conforman un conjunto de normas tutelares dictadas al amparo de un modelo social que entrega en forma casi exclusiva el cuidado de los hijos a las madres. De allí, entonces, que el sentido básico de estas disposiciones sea proteger el embarazo, a los niños menores de dos años y asegurar que las madres que trabajan puedan mantener su sustento, que no sean despedidas por causa del embarazo o de la maternidad y, en último término, que se les reconozcan facilidades para reinsertarse al trabajo después del parto, tales como la sala cuna y el derecho de alimentos.

Por otra parte, es importante tener en consideración que las normas de protección a la maternidad fueron dictadas en un contexto social de escasa participación laboral de la mujer, de allí que algunos de estos derechos son entendidos como una obligación del empleador (v. gr. la sala cuna), como asimismo, tomando como referencia el modelo clásico de la empresa fordista taylorista bajo cuyo alero se fue configurando el Derecho del Trabajo ${ }^{62}$. Esto último resulta evidente si se contrasta con el reconocimiento del derecho a la sala cuna en el artículo 203 ст., уa que la primera opción que plantea el legislador para que el empleador cumpla esta obligación es teniendo "salas anexas e independientes del local de trabajo, en donde las mujeres puedan dar alimentos a sus hijos menores de dos años [...]", es representativo de un tipo de empresa mediana o grande ${ }^{63}$ en la

${ }^{62}$ En detalle: CaAmaño, Eduardo, Las transformaciones del trabajo, la crisis de la relación normal y el desarrollo del empleo atípico, ob. cit., pp. $25 \mathrm{~s}$.

${ }^{63}$ En ese esquema de organización empresarial el número de 20 trabajadoras como requisito para el nacimiento de la obligación de proporcionar sala cuna no resulta 
que exista el espacio físico para mantener una sala cuna. En la actualidad, a partir de las implicancias que supone la descentralización productiva ${ }^{64}$ y la necesidad de las empresas de reducir su tamaño y especializar sus procesos productivos, resulta casi absurdo que los empresarios para cumplir esta obligación se vean en la necesidad, por ejemplo, de contratar parvularias o comprar juguetes, si el giro de la empresa es la producción de colchones. No obstante, desde la perspectiva de la empresa fordista, una obligación pensada en los términos citados no resultaba absurda, ya que guardaba plena relación con el modo integral y no especializado de entender la actividad productiva empresarial.

Por lo tanto, cabe concluir que ya la actual protección a la maternidad requiere de una revisión con miras a adaptarla al nuevo contexto social y económico en el que se desenvuelve el empleo femenino, más aún, si se considera el aumento creciente que éste ha experimentado. Además, resulta evidente que se requiere incorporar en nuestra legislación laboral disposiciones que den posibilidad de desarrollo equitativo a la demanda de compatibilización de trabajo y vida familiar, pues salvo el permiso paternal del artículo 195 inciso $2^{\circ}$ CT., que constituye un ejemplo aislado y no integrado de una búsqueda por promover que los padres trabajadores puedan participar de mejor manera en el cuidado de los hijos, no existe una regulación sistemática, ni una política social continua y coherente que contribuyan a hacer realidad de manera efectiva la igualdad de oportunidades laborales entre hombres y mujeres.

Con todo, y sin pretender agotar el tema, no se puede obviar que en nuestra legislación laboral existe un potencial no suficientemente explorado para aumentar las posibilidades de armonización de trabajo y vida familiar, como es el caso concreto del trabajo a tiempo parcial regulado en los artículos 40 bis y siguientes Ст. ${ }^{65}$ En efecto, la circunstancia de que el trabajo a tiempo parcial suponga que el trabajador preste servicios al

desproporcionado, pero si se contrasta esa visión con la actual configuración de las empresas, representada mayoritariamente por las PYMEs, no cabe duda que la exigencia legal del artículo 203 CT. implica excluir del goce de un derecho tan importante como este a un enorme número de mujeres, pues en las PYMEs resulta casi imposible que existan veinte trabajadoras. En definitiva, los cambios en la organización empresarial derivados de una nueva configuración del orden económico internacional terminan transformando algunos derechos de protección a la maternidad en verdaderos privilegios, con lo que se trastoca su sentido tutelar original.

${ }^{64}$ Ver: Ugarte, José Luis, La descentralización productiva: la nueva moda en las relaciones laborales, en Revista Laboral Chilena (enero 2001), pp. $58 \mathrm{~s}$.

${ }^{65}$ CaAmaño, Eduardo, Conciliación de trabajo y vida familiar. Un análisis desde la perspectiva del Derecho del Trabajo, ob. cit., pp. 59 s. 
empleador por un tiempo reducido, en relación con el tiempo al que se obligan los trabajadores contratados en un régimen común de acuerdo al artículo 22 Ст. y, además, la posibilidad de que el tiempo de trabajo se pueda distribuir de manera flexible ${ }^{66}$, configuran indudablemente un escenario propicio para los trabajadores con responsabilidades familiares. Esto se explica, porque este grupo de trabajadores y, en particular las mujeres, por ser quienes normalmente deben asumir dichas responsabilidades en nuestra sociedad, cuentan en virtud de la actual regulación del trabajo a tiempo parcial en el Código del Trabajo con una importante herramienta que les puede facilitar su incorporación al mercado de laboral o que les podría asegurar que no se vean en la necesidad de tener que abandonar un puesto de trabajo para asumir el cuidado de un hijo o de un familiar directo. No obstante, estas ventajas no se pueden alcanzar de manera espontánea, por el sólo hecho de haberse dictado una regulación especial sobre la materia, sino que requieren de su valoración por parte de los actores sociales, así como de una política social proactiva y de incentivos adecuados que fomenten que tanto hombres como mujeres cuenten con más alternativas de distribución de sus tiempos de trabajo cuando desean asumir sus responsabilidades familiares. Por tanto, hay una tarea pendiente en este sentido.

\section{CONCLUSIÓN}

Para concluir basta reiterar que el tema de la adecuada compatibilización entre vida laboral y familiar y el reforzamiento de la igualdad de oportunidades en el empleo entre trabajadoras y trabajadores es una materia aún no resuelta a cabalidad y cuya solución no supone necesariamente la implementación de medidas de orden legislativo. De esta manera, por ejemplo, se hace difícil imaginar una norma específica en el Código del Trabajo sobre la materia ${ }^{67}$, sin perjuicio que algunos aspectos relacionados con esta temática ya cuentan con una regulación expresa, como es el caso de la protección a la maternidad.

Por lo anterior, las medidas que deberían adoptarse para avanzar en la conciliación de trabajo con responsabilidades familiares pasan por replantear instituciones tradicionales del Derecho del Trabajo para adaptarlas a la nueva realidad social, así como por el diseño e implementación de políticas

${ }^{66}$ Importantes ventajas prácticas en este sentido podrían obtenerse de una correcta aplicación de la modalidad de trabajo a tiempo parcial con alternativas de distribución de la jornada de trabajo, regulada en el artículo 40 bis CT.

${ }^{67}$ En este sentido: Servicio Nacional de la Mujer, Análisis sobre experiencias en empresas sobre compatibilización de vida laboral y familiar, ob. cit., p. 101. 
sociales, de empleo y económicas en cuya elaboración debieran participar junto al Estado las organizaciones de trabajadores y empleadores del país, pues todos son, en lo que respecta a esta materia, importantes agentes de cambio $^{68}$. Así lo ha entendido también la ort en el Convenio $\mathrm{N}^{\circ} 156$, al señalar el tipo de medidas que deben adoptar los Estados que lo han ratificado para obtener el fin perseguido por este instrumento internacional.

Finalmente, no se debe obviar que el tema de la compatibilización de la vida familiar y laboral no es un tema que implica sólo a las mujeres trabajadoras para que los hombres asuman un rol más activo frente a las responsabilidades derivadas del cuidado de los hijos o de otros familiares directos, sino que, más bien, es un tema que involucra a toda la sociedad $y$, en importante medida, dice relación con el proyecto o modelo de sociedad que se pretende construir en el país. Desde esta perspectiva, un país como Chile que aspira a alcanzar el desarrollo y el consecuente bienestar económico y social de los países que se ubican en dicha escala, debe plantearse activamente temas como éste y transformarlos en un principio orientador del modelo a seguir, por su innegable vinculación a los valores de la igualdad de oportunidades, la solidaridad y la justicia social, sin los cuales el bienestar económico se puede transformar en un mero concepto vacío y, por lo mismo, carente de significado para la población.

[Recibido el 31 de octubre y aceptado el 19 de noviembre de 2007].

\section{BIBLIOGRAFÍA}

Abramo, Laís - Rangel, Marta (editoras), Negociación colectiva y equidad de género (Santiago, Oficina Regional de la ort para América Latina y el Caribe, 2005).

Arriagada, Irma, Los límites del uso del tiempo: dificultades para la conciliación de familia y trabajo, en Políticas hacia las familias, protección e inclusión sociales (CEPAL, Reunión de Expertos, 28 y 29 de junio de 2005), disponible en: www.cepal.cl.

Binnstock, Hanna, Hacia la igualdad de la mujer. Avances legales desde la aprobación de la Convención sobre eliminación de todas las formas de discriminación contra la mujer, en Serie Mujer y Desarrollo No 24 (Santiago, CEPAL, 1998).

Borrajo, Efrén (Editor), Nueva sociedad y Derecho del Trabajo (Madrid, 2004).

${ }^{68}$ En este sentido: Tortuero, José Luis, 50 propuesta para racionalizar la maternidad y facilitar la conciliación laboral, ob. cit., p. 35: "En efecto, la estrategia que persigue la integración de la perspectiva de la igualdad en todas las políticas normativas en oposición a la mera elaboración de proyectos destinados específicamente a las mujeres sería insuficiente si no incorpora la problemática de la conciliación de la vida familiar y laboral, en la medida que se ha demostrado que la concepción sectorial de políticas de igualdad, imprescindible, antes y ahora, no han logrado su objetivo final". 
CaAmaño, Eduardo, Comentarios en torno al nuevo dictamen de la Dirección del Trabajo sobre la extensión temporal del derecho a dar alimentos, en Revista Laboral Chilena 122 (diciembre 2003).

CaAmaño, Eduardo, Conciliación de trabajo y vida familiar. Un análisis desde la perspectiva del Derecho del Trabajo, en Revista de Derecho 16 (Universidad Austral de Chile, julio de 2004).

CaAmaño, Eduardo, Las transformaciones del trabajo, la crisis de la relación normal y el desarrollo del empleo atípico, en Revista de Derecho 18 (Universidad Austral de Chile, julio 2005).

CaAmaño, Eduardo, El trabajo a tiempo parcial (Santiago, 2007).

CaAmaño, Eduardo, El derecho a la no discriminación en el empleo (Santiago, 2005).

Carrasco, María José - García-Mina, Ana, El ajuste trabajo-familia desde una perspectiva de género (Madrid, 2005).

Espinoza, Malva, Calidad de vida en el trabajo: reflexiones en torno a la inseguridady el malestar social, en Temas Laborales 18 (septiembre 2001), disponible en www. dt.gob.cl.

Galdames, Liliana, La discriminación de la mujer ante el derecho internacional. Convención sobre eliminación de todas las formas de discriminación contra la mujer (Memoria para optar al grado de licenciada en ciencias jurídicas, Universidad de Chile, Santiago, 1994).

Gil y Gil, José Luis; Ushakova, Tatsiana, Los derechos sociales en la Carta de los Derechos Fundamentales de la Unión Europea, disponible en: http://www.uv.es/ CEFD/5/gil.html.

Groupe D' EXPERTS invitées à la discussion du rapport intermédiaire, Transformation du travail et devenir du droit du travail en Europe (Conférence de Nantes, 25 de octubre 1997), Rapport final (1998).

HeIn, Catherine, Conciliar trabajo y las responsabilidades familiares. Ideas prácticas de la experiencia global, en Colección Informes de la Organización Internacional del Trabajo (Madrid, Ministerio del Trabajo y Asuntos Sociales, 2006).

Henríquez, Helia; Riquelme, Verónica - CÁrdenas, Tatiana, Las normas que protegen la maternidad en Chile: el comportamiento de las empresas, en Cuadernos de Investigación 3 (Dirección del Trabajo, mayo 1997).

Instituto Nacional de Estadísticas, La fecundidad en Chile. Situación reciente, noviembre 2006, disponible:www.ine.cl/canales/chile_estadistico/demografia_y_vitales/demografia/pdf/fecundidad.pdf.

Martínez, Jesús, Nuevas formas de familia y Derecho del Trabajo y de la Seguridad Social, en Borrajo, Efrén (editor), Nueva sociedad y Derecho del Trabajo (Madrid, 2004).

Martínez, María Pilar, El papel de las relaciones familiares en el ajuste familia-trabajo, en Carrasco, María José - García-Mina, Ana (editoras), El ajuste trabajo-familia desde una perspectiva de género (Madrid, 2005).

Orellana, Ana María, Medidas para promover la conciliación de la vida familiar y laboral de las personas trabajadoras. Análisis de las Directivas Comunitarias 92/85 y 96/34 y lagunas en su transposición al ordenamiento interno español, en Revista del Ministerio del Trabajo y Asuntos Sociales 37 (Madrid), disponible en www. mtas.es.

Reveco, Carla, Normas de protección a la maternidad en el derecho del trabajo y su aplicación respecto de los padres adoptivos (Memoria para optar al grado de licenciada 
en ciencias jurídicas, Pontificia Universidad Católica de Valparaíso, Valparaíso, 2005).

Riquelme, Verónica, El tiempo de trabajo, en Temas Laborales 11 (Dirección del Trabajo, enero de 1999), disponible en www.dt.gob.cl.

Servicio Nacional de la Mujer, Análisis sobre experiencias en empresas sobre compatibilización de vida laboral y familiar, en Documento de Trabajo No 67 (1999).

Servicio Nacional de la Mujer, Conciliación entre la vida familiar y la vida laboral de trabajadores y trabajadoras chilenoslas, en Documento de Trabajo No 76 (2002).

Servicio Nacional de la Mujer, Análisis de los costos y beneficios de implementar medidas de conciliación de vida laboral y familiar en la empresa, en Documento de Trabajo No 84 (2003).

Todaro, Rosalba; YÁÑEz, Sonia, El trabajo se transforma. Relaciones de producción y relaciones de género (Santiago, 2004).

Tortuero, José Luis, 50 propuestas para racionalizar la maternidad y facilitar la conciliación laboral (Navarra, 2006).

Ugarte, José Luis, La descentralización productiva: la nueva moda en las relaciones laborales, en Revista Laboral Chilena (enero 2001).

Zamorano, Pilar, Descansos, subsidios e inamovilidad laboral por causa de maternidad (Memoria de prueba para optar al grado de licenciada en ciencias jurídicas, Universidad de Chile, Santiago, 2000). 